\title{
Özü Fitrata Dönük Bir Ayet Olarak Çocuk
}

\author{
HÜSEYIN AKIN
}

Din doğaya uyum üzere yürüyüşünü sürdüren bir sistemdir. Doğanın en önemli özelliklerinden biri "çelişmezlik"tir. Bir oluşun diğerini tutmaması gibi çelişik durum doğanın ruhuna aykırıdır. Evet doğanın ruhu vardır. Şayet doğa yani tabiat ruhtan mahrum olmuş olsaydı içeriksiz malumat yığınından öteye geçemeyecekti. Yapaylığı kabul etmeyen tabiat kendi özüne saldırıp muhalif olan her şeye karşı bir şekilde savunma geliştirir. Dinin bütün umdeleri bu sisteme tabidir. İhtiyar sahibi olmayan, insanın dışındaki varlıkların ait olduğu düzeneğe sünnetullah, irade sahibi olan insanın temellerinin oturtulduğu iklime fitrat denir. Bütün tevhidi sistemler insanın doğuştan masumiyetini müdafaa eder. Bu anlamda her doğan temiz ve günahsız doğar ilkesi esastır. İnsanın doğuştan günahkâr kabul edilmesi ve beraberinde vaftiz uygulaması tevhidi bir sapmadır. Semavi dinlerin fitratla bağının koparılmasına yönelik bir yaklaşımdır tevarüs edilen "ilk günah" anlayışı. Din eğitimi ve çocuk pedagojisi fıtri temellerini kaybettiğinde dinin öngördüğü yetişkin insan seviyesi de bundan olumsuz anlamda etkilenecektir. İnsanın doğa ile ilişkisi içinde anlama, kavrama ve uygulama zorluğu barındırmayan bir ilişki olduğu için din ile münasebeti de kolaylık ve de doğallık üzere seyreder. İnsan hareket ve davranışlarının güzelliğini konu alan ahlâkın uygulanabilirliğinde de bu kolaylığın rolü büyüktür. Arapça'da "seciye, tabiat, huy" gibi mânalara gelen ahlâk hulk veya huluk kelimesinin çoğuludur (Çağrıc1). Ahlâkın "hulk" yani "yaratılış" anlamını içerdiğini dikkatten kaçırmamak lazımdır. Burada güzel davranışlar ya da davranışlardaki güzelliklerin kaynağında insanın dünyaya gelişiyle birlikte doğuştan getirdiği temizlik ve de saflığa işaret vardır.

- GÖRÜS-

Çocuk ve

HÜSEYIN AKIN, akinakinhuseyin@hotmail.com Sair, Yazar doi: https://doi.org/10.47646/CMD.2021.264 
Mahrecine uygun bir tanım yapacak olursak ahlâk: Yaratılıştaki güzelliğe geri dönme çabasıdır. İnsan ömrünün yaratılışa en yakın çağı kuşkusuz çocukluk çağıdır. Çocukluk yetişkinliğe -aklı kullanma sorumluluğunaulaşmaya yumuşak bir geçiştir. İnsan doğar doğmaz aklı kullanma ile muhatap kılınsaydı bu hem doğaya ters hem de gücünün çok üzerinde bir ağırlık oluşturacaktı. Çocukluk, realiteyle dünya acemisi insanın direk temasının oluşturacağı travmanın önünde bir çeper vazifesi görür. Çocuk kâinat içerisinde yer alan kevni ayetlerin en yalın ve en okunaklı olanıdır. Dolayısıyla doğayı tahrip etmekle çocuğu ve çocukluğu tahrif etmek arasında bir fark yoktur. Hatta doğanın görünür tahribatının en somut biçimi çocukluk çağı üzerinde yapılan tahrifattır diyebiliriz. Çocukların erken büyüdüğü bir çağda dinin muhatap alıp usuller geliştirebileceği bir çocuk olgusundan da bahsetme imkânı yoktur. Zira çocuk olma süreci biyolojik safhanın ötesinde daha çok psişik ve zihinsel bir safhadır. Kur'an-1 Kerim'de ekin ile neslin fesadının birlikte ifade edilmesi çocuk-tabiat bütünlügüune de dikkat çekme amaçlı olsa gerektir (Yazır):” İş başına geçti mi yeryüzünde bozgunculuk çıkarmak, ekini ve nesli helak etmek için koşar. Allah ise bozgunculuğu sevmez."

Çocukluk insanlığa atılıı̧ ilk adımdır. Bu ilk adım onun fıtratla ilişkisini belirler. Fıtrî olanda yanlış, kötü ve günah olana karşı kabiliyetsizlik ve elverişsizlik vardır. "Çocuk istese de kötülük yapamaz" denilemez, çünkü kötülük yapmaya niyet ederek onu isteme gibi bir güçten yoksundur. Bu yoksunluktan masumiyet doğar. Fitrat kelimesinin köküne indiğimizde de bu masumiyeti temellendirecek anlamlarla karşılaşıyoruz. "Belli yetenek ve yatkınlığa sahip oluş” ifadesiyle özetleyebileceğimiz bu kavramı "içinde bulunduğu yetenek ve yatkınlığın dışına çıkmayan bu anlamda bir arzu ve irade de göstermeyen" biçiminde tavzih etmemiz mümkündür. Çocuklardaki bu sınavdan muaf olma masumiyeti yetişkinlerin onlara terbiyevi yaklaşımlarında usul geliştirmesini zorunlu kılmıştır. Zira din söz konusu olunca çocuk psikolojisi ve pedagojisi başka alanlardan daha çok önem arz etmektedir. Müslüman din anlatıcılarının yaygın kullanım alanı içerisinde olan şu hadis "fıtrat"ın altını çizerken bir taraftan da çocukların inanç bağlamında değişim ve dönüşüm sebepleri üzerinde dış etkilerin ne denli müessir olduğunu da dikkatlere sunmaktadır: "Dünyaya gelen her insan fitrat üzere doğar; sonra anne ve babası onu yahudi, hıristiyan, Mecûsî

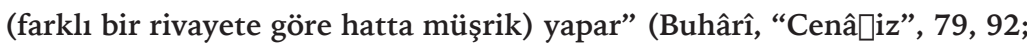
Müslim, "Kader", 22-25). Bu hadiste çocuk acaba savunmasız bir varlık olarak mı görülmektedir? Anne babası ve çevresi tarafından aşağıya çekilen biri mi? O vakit çocuk şekil alan değil şekil verilen bir varlık konumuna yerleştirilmiş olmuyor mu? 
Çocukluk çağı üzerinde her türlü deneysel yönlendirmenin yapıldığı bir süreç mi gerçekten? Hadisin asıl vurgulamak istediği şey çocuğun fitratını korumak ve ona iklimini bozacak telkin ve tebliğ yapmamak, empozede bulunmamaktır. İslamî pedagojiye uygun olan çocuğun fitratını muhafaza etmek ve bu fitrat üzere yetişip gelişmesini sağlamaktır. Çocuğun fitratı korunduğu zaman dinî terbiyeye de uyumlu hale gelir. Tabiat ifrat ve tefrite kaymadan, her türlü aşırılıktan uzak, normal olana yakın durmayı eksen alır. Bu meyanda fitrat çocuğu mutedil ve mutavassıt bir insan olmaya hazırlar. Çocuktaki saflık, duruluk ve günahsızlık fıtratın ona bahşettiği bir normallik ölçüsüdür. Herhangi bir normla mükellef olmadan daha o çağlarda normali yakalayıp yaşamak insan olmakla ulaşacağımız aşama konusunda da bilgi vermektedir. Bu normale kısaca "Hanif" demek mümkün: "Sen yüzünü Hanîf olarak dine, Allah insanları hangi fitrat üzere yaratmışsa ona çevir" (Rûm Suresi- 30/30). Kur'an'ın diliyle "Hanif” şirkten berî bir Allah inancına sahip küfür ve sapkınlıklardan uzak bir tevhit anlayışının adıdır. Saf ve yalın tevhit anlayışıyla çocukların doğalarında yaşayıp da dile getiremedikleri İslami ruh ve atmosfer aynı noktada birleşip buluşurlar. Dinî Gelişim Kuramcısı Ronald Goldman'a göre kutsallık hissini yaşayan 3-6 yaş dönemindeki çocukların, duygularını tam olarak ifade edememelerinin nedeni ise deneyim eksikliği, entelektüel olgunlaşmamışlık, sınırlı kelime dağarcıklarına sahip olmalarıdır. Eğitim kavramının iradeye dayalı bir süreci ihtiva ettiğini göz önünde bulundurduğumuzda (Eğitim: Bireyin davranışlarında kendi yaşantısı yoluyla kasıtlı olarak istendik değişme meydana getirme sürecidir.) çocukların terbiye edilmesi onları değiştirmeye yönelik bir uğraş değil aksine davranışlarına dek uzanan fitrî dünyalarını koruyup kollama çabasıdır. Burada dikkat edilmesi gereken şey çocuğun yakın çevresi tarafından bulunduğu yerden başka taraflara doğru çekilip yönlendirilmesine engel olmaktır.

Çocukluğun yetişkinlik için bir arşiv olduğunu, çocuklukta yığınak yapmış bilinçaltı unsurlarının ileri yaşlarda tezahür ettiğini, Freud'un tabiriyle çocukluğun "büyükklüğün babası" olduğunu da bu arada dikkatlerden kaçırmamak lazımdır. Çocukluk döneminde yaşanan ve de yaşanmayan her şey çocuğun ileriki yaşlarını belirgin şekilde etkileyecektir. Çocuğun çevresi dini hayata ne denli yakınsa çocuğun dinle ilgili yaklaşımları kuvveden fiile daha çabuk yansıyacaktır. Burada yokluk ve mahrumiyet kadar azlık ve çokluk da çocuk zihinsel ve ruhsal gelişimini negatif anlamda etkileyecektir. Dindar bir ailede yetişen çocuk dini hassasiyetlere daha erken ulaşabileceği gibi dinsel problemlerle de daha erken tanışacaktır. Çocuğun din ile ilişkisinin kalıcı olabilmesi için bilişsel öğretiden ziyade duyuşsal yaklaşımın daha büyük katkısı vardır. Çocuklukta biriktirilen 
din ve soyut dünyaya dair güzel hatıraların yetişkinlik dönemlerinde dine karşı önyargıları kırıp olumlu duyguları besleyeceği aşikardır. Din adını verdiğimiz kavram çocukluk ve ilk gençlik yıllarında "hayat"tan bağımsız bir şey değildir. Çocuk ve ergen tasavvur ve tahayyülü hayatla dinin arasını açmaz. Bu kuşaklara dinden bahsetmek isteyenlerin hayattan bağımsız bir başlık atmamaları gerekir. Goldman'ın üzerinde durduğu şey çocukların ve genç insanların zihniyle uyumlu bir din anlatısının yanı sıra dini anlayıp özümseyecek körpe dimağları çok iyi tanımaktır: "Eğer mümkünse, din eğitimcileri için günlük yaşam içinde kendi öğrencilerini birkaç gün izleyerek geçirmek iyi olur. Şayet öğretmenler, eğittikleri çocukların tecrübelerini, dilini, kavramlarını, meraklarını, ihtiyaçlarını, ilgilerini, sevinçlerini, zevklerini, ruhsal durumlarını ve tutumlarını algılayabilirlerse, din öğretiminin, öğrencilerin yaşamları ile daha yakından temas halinde olabileceğini düşünüyorum." (Goldman, s.94). Hayatla çatışan, hayatı anlamaya yaklaşmayan, şefkati hayatın şefkatinden alt seviyede olan, neşesi hayatla boy ölçülmez olan bir din eğitimi çocukların ve gençlerin hem omurgasını hem de kimyasını bozacaktır.

Çocuk anne baba nezdinde bir göz nuru, hayatın neşesi ve dünyanın süsüdür. Mal, mülk, kadın başta olmak üzere çocuk da ebeveyn için bir sınavdır. Dini literatürde buna "fitne" de denir (Nahl, 16/72; Kehf, 18/46; Şuara, 26/132-134). Fitne halk arasında kullanıldığı gibi kaba anlamıyla "ara bozucu" anlamının çok daha ötesinde cezbedici, çekici, meftun edici olan demektir ki insana yeryüzünde varlık sebebini unutturan her çekici ve bağlayıcı unsur fitne olarak isimlendirilir. Çocuğa yaklaşım ve ilgi çocuğun kendi varlığını ebeveynde unutacak şekilde marazi bir hal almamalıdır. Bu yaklaşım hem çocuğun kendi kişiliğini bulmasının önünde bir engel hem de Tanrı-İnsan ilişkilerinin özüne zarar verecek boyutta bir aşırılık oluşturmaması gerekir. "Mallarınız ve çocuklarınız ancak birer imtihandır; Allah katında ise büyük bir mükâfat vardır.” (Teğabun, 64/15). İslam dini perspektifinden baktığımızda "çocukla sınanmak" çok yönlü bir imtihanı içerisinde barındıran bir mesuliyet durumudur. İnsan geçici süre elinde bulundurduklarına emanet gözüyle bakmalıdır. İnsanın eşi ve çocuklarıyla ilişkisi sahibiyet değil aidiyet ilişkisidir. Aidiyet sorumluluğu da beraberinde getirirken sahibiyet hesap sorulamazlığı ve kendine sahip kıldığı şeye karşı tam bir inisiyatifi ifade eder. Çocuğa dini duyarlık ve prensipler serbest düşünme ve karar verme yetenekleri örselenmeden verilmelidir. Yetişkin

Çocuk ve Medeniyet 2021/2 insanların birçoğu önyargılara ve peşin fikirlere dayanan negatif din algılarının özünde dine dair çocuklukta yaşadıkları travmaların olduğunu söylemek sanırım abartı olmaz. 
Din malumat değil öz ve esastır. Bu durum çocuk için daha bir böyledir. Çocuk zihnini din adına teferruatla meşgul etmek çocuğun gelecek günlerde yürüyeceği yollar üzerine yığınaklar oluşturmaktan farksızdır. Dinde öz bilgi tevhittir. Çocuğa "Tanrı" düşüncesi bu "birlik" çerçevesinde verilmelidir. Tanrı imgesi çocuğun zihnine sağlıklı şekilde yerleşmemişse din ve dine dair esaslar hiçbir zaman doğru bir zeminde olmayacaktır. Kur'an-1 Kerim'in Lokman Suresi'nde yer alan ayetler çocukta tevhit anlayışını yerleştirmeye dönük terbiye örnekleridir: “Lokman'ın oğluna öğüdünü hatırla! O şöyle öğüt veriyordu: "Yavrucuğum! Allah'a asla ortak koşma! Çünkü şirk, büyük bir zulümdür." (8) Burada olumlu tevhit vurgusundan evvel olumsuz şirk vurgusu yapılmış olması çocuğun doğasında zaten fitri olarak tevhit ruhunun varlığına dolaylı atıftır. Zira şirk fitrat dışı bir yaklaşım biçimidir. Doğasını koruyamadığında her çocuğu muharref bir gençlik ve yetişkinlik bekleyecektir.

Tevhidî fitratın korunması yanında aynı surede çocuklara din eğitiminde yer alan ikinci husus namaz ve ardından da mahremiyet eğitimi gelmektedir. Kur'an'da ergenlik çağına ulaşmamış çocukların anne babalarının odasına girmeleri için onlardan izin istemeleri belirtilirken ergenliğe girmiş olanlar için bu kuralın kapsamı biraz daha genişletilmektedir (Nur-24/5859). Çocukların din eğitimi onların belli başlı duaları ve dini metinleri okuyacak hale gelmesi ya da ezberlemesi değildir. Ruhlarına, mizaçlarına ve karakterlerine sinecek güzelliklerle onları tanıştırmaktır asıl. Büyükler gösterir çocuklar gösterilen şeye büyük bir arzuyla yaklaşırlar ve bu münasebetten eğitim meydana gelir. İsteğin ve iradenin saf dışı edildiği bir tedrisatta eğitimden bahsetmek mümkün değildir. Burada olsa olsa metazori öğretme ve öğrenme vardır. Din eğitiminde çocuğun namaza yönelmesi ve namazla tanışması namaz kılmasından önde gelir. Zira hiçbir çocuğa namaz mükellefiyet yaşına ulaşmadıkları için farz değildir. Lokman Suresi 17'de yer alan "Ey yavrucuğum! Namazı kıl; iyiliği emredip (öğütleyip) kötülükten engelle (sakındır); başına gelenlere de sabret! Şüphesiz ki bu, azmetmeye değer işlerdendir." ayet çocuğa vakti geldiğinde mesul olduğu (namaz, emr-i bil maruf nehy-i anil münker, sabir gibi ibadet ve hasletleri yerine getirmesi konusunda sıkı sıkı tembih niteliğinde olsa gerektir. Şayet böyle değilse Lokman (as.)'ın “yavrucuğum!” diye nasihat ettiği evladı buluğ çağında olmalıdır. Ayette Lokman (as)'ın nasihatlerine muhatap olan evladı kuvvetle muhtemel çocukluk çağının üstünde delikanlılık yaşındadır. Her iki durumda da babanın evladına din eğitimi noktasında çok önemli yaklaşımlarına rastlıyoruz. En başta şefkat dili ve hitap biçimi dikkat çekiyor. Büyük mesajların çocuk katında büyük bir şahsın (baba) dilinden aktarılması sorumlu olduğu şeyler karşısında çocuğu olgunlaştırır. 
Hz. Muhammed'in torunları ile ilişkisi yaşam merkezli din eğitimine en güzel örnektir. Namaz kılarken uzun süre secdeden kalkmayan Hz.Peygamber'e kaygılanan sahabe tarafından bu durum sorulduğunda onun verdiği cevap çok incelikli ve bir o kadar da öğreticidir: "Oğlum (Hasan ya da Hüseyin) secdeye vardığımda sırtıma çıktı. Evde bu âdeti edindiğinden, onu sırtımdan atamadım ve böylece secde uzun sürdü." (İbn Hanbel). Hz. Peygamberin torununa yaklaşımında çocuklara din eğitimi konusunda çok önemli dersler vardır. Çocuğun oyun dünyası içerisinde dinî şekil, motif ve sembolleri görüp tanıması bilinçaltında olumlu anlamda çok müessir izler bırakacaktır. Oyun çocuğun hayatla ilişki kurma biçimidir. Oyunu ıskalayarak çocuğu dini sorumluluklarla muhatap kılmak fıtrata aykırılık teşkil edeceğinden müspet kalıcı davranışların oluşmasını engelleyecektir.

Çocuğun anne babası namaz kılarken taklide yönelmesi ya da bu hareketleri oyunlaştırması namaz kılan kişinin disiplinini bozuyor gibi görülse de çocuğun dinî dünyasında ileri vadede bilgiye dönüşen güzel hatıralara vesile olacaktır. Teravihte gülen çocuklar bazı yetişkin ya da ihtiyarların nazarında camide olmaması gereken bir tavır içerisinde görülebilirler. Halbuki biraz daha yakından ve içten bakıldığında çocuğun şakalaşmalarına katıp gülüşüne yüklediği dinî bilgi ve duyarlık başka hiçbir eğitim-öğretim biçimiyle elde edilebilecek bir şey değildir. Çünküi hayatın içerisinde biraz muzipçe de olsa yaşayarak öğrendiklerini daha kalıcı kılabilmektedirler. Soyut düşünme yetenekleri tam gelişmediği için çocukların kutsalı kavraması oldukça zordur. Anlatarak da bu konuda mesafe kat edilemez. Bu sebepten didaktik anlamda kutsalı kavramanın yerini kutsalla tanışmak almalıdır. Ebeveyn tarafından kutsal mefhum, mekân ve günler çocukların ilgisine sunularak onlarla doğal süreçte tanışması sağlanır.

Tanrı biz insanlarla iletişim kurarken nasıl bizim seviyemize iniyor ve ilahî mesajı insan olma kapasitemizi esas alarak beyan ediyorsa, ilahi mesaj karşısında idrak olarak çocuk mesabesinde olan biz yetişkinler de çocuklara aynı metot ve hassasiyeti göstermeliyiz. Özellikle erken dönem çocukluk sürecinde çocuksu bir Tanrı anlayışı hakimdir. 10-12 yaşlarına doğru ise bu çocuksu bakış yerini biraz daha oturmuş bir Tanrı anlayışına bırakır. Çocuklukta hızlı zihinsel gelişim birçok soyut kavram gibi Allah anlayışında da irtifa kazanır. Dünyaya nasıl geldikleri ile ilgili sorulara ebeveynin geçiştirmeli cevaplar vermesi gibi yaratılış ve Tanrı konusunda da anne babalardan tatmin edici bir cevap alamadıklarını fark ederler. Bu 2021/2 
daha güvenebileceğe cevaplara yönelmesidir. Özellikle 2 ila 5 yaş arasında çocukların zihnini cezalandırıcı Tanrı anlatısından korumak icap eder. Tanrı korkulan değil sevilen, güvenilen ve varlığı ile mutlu olunandır. "Allah'tan korkmak" ifadesi hangi anlamda kullanılırsa kullanılsın coğrafyamızdaki çocukların dünyasında "korkunç olan bir varlık"la birlikte düşünülmeye müsait bir ifadedir. Çocukluk dönemi asude bir uyku dönemidir. Çocuk bir oyunun en heyecanlı yerinde bu uykudan uyanır. Tasavvur ve tahayyül dünyası masal imgeleriyle doludur. Çocuk zihni mucizevi, aşkın dinî anlatı ve metinleri bu minval üzere algılamaya müsaittir. Bazı bilgilerin verilmesinde çocuğun duygu ve zihin gelişimini dikkate almak gerekir. Zamanından evvel verilen kimi bilgiler çocuğun psişik dünyasına negatif etki yaratabilir. Çocuğun soyutla bağdaşık bir zihin yapısı geliştirebilmesi için hayal imkânlarından ve masal unsurlarından azami yararlandırılması isabetli olacaktır. Ebeveynin bu dönemlerde fiili yaklaşım ve yakınlaşmayı esas alıp sözel uyarı ve nasihati mümkün mertebe azaltması gerekir. Aksi takdirde gittikçe değeri düşen söz güçten de düşerek tesirini kaybetmekle yüz yüze gelecektir. Çocukluk çağı idealler değil modeller çağıdır. Ne kadar ilgi çekici davranış biçimi varsa çocuk bunları üstünde denemek ister. Kendine en yakıştığına kanaat getirdiğini benimser.

Geleneksel din eğitim usulleri ne yazık ki ezber yaklaşımlardan kurtulmuş değil. Çocuğu tutup yaz tatillerinde mevsimlik Kuran kurslarına yazdırmak, birlikte camiye gitmek, abdest ve namazı öğretmek vb. mahdut bir alanı aşamayan hassasiyetler elbette önemli fakat özellikle değişen ve gelişen zaman için bu anlamda yetersiz gayretlerdir. Özellikle ahlâki umdeler, davranış biçimleri, fiziki ve sosyal ortama karşı sorumlulukları, estetik duyarlık ve hayatı coşkuyla yaşama becerisi de bu eğitimin vazgeçilmezi kabul edilmelidir. Çocuklarda din eğitimi sanıldığı gibi çocukluk çağının bahçesini yaban otlarından temizlemekten ibaret de değildir. Çocukluğun imar ve inşası için çalışıp bir nevi gençlik, yetişkinlik ve hatta ihtiyarlık çağlarına yatırım yapmaktır. Zira insanın temeli ve insanlığın giriş cümlesi çocukluğundadır. Çocuğu hayata ve hayat ötesine eğitmenin yerini bugün maalesef "başarıya eğitmek" almıştır. Başarıyla eğitmek ile başarıya eğitmek arasında çok büyük mahiyet farkı vardır. Hedefi tam isabet ettiremeyen her çocuğun başarısız addedildiği bir toplumda normali yakalayamayan uçlarda gezinen yetişkin insanların olması gayet doğaldır. Fıtrat ilahî mahreçli ve çocukluk çağı bir şiirin Tanrı'dan gelen ilk dizesi gibi yetişkinliğin ilham kaynağı ve işaret fişeği ise bu çağa vereceğimizden çok bu çağdan alacağımız çok şey var demektir. 


\section{Hüseyin Akın}

\section{Kaynakça}

Çaḡrıcı, M., İslam Ansiklopedisi Ahlâk maddesi. Erișim adresi: https://islamansiklopedisi.org.tr/ahlak Goldman, E. R. (2004). Dinî Anlayıș Psikoloḡu (ed. A. R. Aydın). Birey ve Din-Din Psikolojisinde Yeni Arayıșlar. İstanbul: İnsan Yayınları.

İbn Hanbel, A. (ö. 241/855). Müsnedü'l-Imâm Ahmed b. Hanbel.

Yazır, Elmalıı Hamdi. Kur'an-ı Kerim Meali. 